\title{
How can we alter our carbon footprint? Estimating GHG emissions based on travel survey information
}

\author{
Anais Mathez \\ Geography Department \\ McGill University \\ Burnside Hall, 805 Sherbrooke St. W. \\ Montréal, Québec, H3L 3T1 Canada \\ Email: anais.mathez@mail.mcgill.ca \\ Kevin Manaugh \\ School of Urban Planning \\ McGill University \\ Suite 400, 815 Sherbrooke St. W. \\ Montréal, Québec, H3A 2K6 Canada \\ E-mail: kevin.manaugh@mail.mcgill.ca

\section{Vincent Chakour} \\ Department of Civil Engineering and Applied Mechanics \\ McGill University \\ Macdonald Engineering Building, 817 Sherbrooke St. W. \\ Montréal, Québec, H3A 2K6 Canada \\ Email: vincent.chakour@mail.mcgill.ca
}

\author{
Ahmed El-Geneidy \\ School of Urban Planning \\ McGill University \\ Suite 400, 815 Sherbrooke St. W. \\ Montréal, Québec, H3A 2K6 Canada \\ Tel.: 514-398-8741 \\ Fax: 514-398-8376 \\ Email: ahmed.elgeneidy@mcgill.ca \\ Marianne Hatzopoulou (corresponding author) \\ Department of Civil Engineering and Applied Mechanics \\ McGill University \\ Macdonald Engineering Building \\ Room 492, 817 Sherbrooke St. W. \\ Montréal, Québec, H3A 2K6 Canada \\ Tel: 514-398-6935 \\ Fax: 514-398-7361 \\ E-mail: marianne.hatzopoulou@mcgill.ca
}

\section{For Citation PLEASE USE}

Mathez, A., Manaugh, K., Chakour, V., El-Geneidy, A. \& Hatzopoulou, M. (2013). How can we alter our carbon footprint? Estimating GHG emissions based on travel survey information. Transportation, 40(1), 131-149. 


\begin{abstract}
The City of Montreal has taken recent initiatives to significantly reduce overall greenhouse (GHG) emissions from the transport sector and has made large investments in alternative transportation. In particular, the City has called upon the participation of all businesses and institutions to further these goals. In light of these recent plans, this study identifies with two objectives: first, to develop a methodology for estimating GHG emissions generated by commuters to McGill University's downtown campus; and secondly, to better understand who, how, and when each commuter to McGill generates travel-related GHG. Mode split, travel distance, age, gender and job category were uncovered by a 2011 travel survey that we conducted across the University, from which daily individual GHG emissions are estimated. Details about these trips not only reveal who the largest polluters are and where they are coming from, but also the seasonality of their emissions. These associations are then used to narrate scenarios which present alternatives to the structure of individuals' commutes by examining the outcomes of selected shifts in travel behavior on total GHG emissions.
\end{abstract}

Keywords: Greenhouse gas emissions, commuting, travel survey, scenario analysis 


\section{INTRODUCTION}

The significant contribution of transportation to greenhouse gas emissions (GHG) is a subject that has received much attention. The literature swells with recent research demonstrating the role and potential of urban transportation in the reduction of anthropogenic GHG emissions. In 2005, transportation was responsible for $23 \%$ of the world carbon dioxide $\left(\mathrm{CO}_{2}\right)$ emissions from fuel combustion, of which the road sector held the greatest share (International Transport Forum, 2008). This global trend points to increased car use, of which urban areas in Canada are no exception, both in terms of vehicle ownership and vehicle kilometers traveled (VKT). The pressure to decrease GHG emissions from the transport sector has pushed large metropolitan areas to heavily invest in transit infrastructure and promote the use of active transportation.

Many governments are aiming for major reductions in GHG generated from transport. This goal was clearly reflected in a declaration made by the City of Montreal, during the United Nations Climate Change Conference in 2005, to achieve a reduction of 30\% of the community's GHG emissions by 2020. In the province of Quebec, the transport sector is responsible for 38\% of total GHG production (Gouvernement du Quebec, 2008). In 2003 alone, transportation emitted nearly 14 million tons of GHG throughout the Montreal metropolitan area (Division du developpement des transports, 2008). The intent of the 2008 Montreal Transportation Plan is to significantly reduce its dependence on cars through massive investment in various forms of public transit and active transportation, including the metro, bus, train, as well as pedestrian and cycling facilities. As part of the strategy to attain these goals, the City has called upon all institutions and businesses to further the objectives of the Transportation Plan by encouraging active transportation and public transit, as well as more appropriate uses for cars such as carpooling and car-sharing.

In light of the growing momentum behind sustainable transport initiatives in Montreal, McGill University, located right in the downtown core and one of the largest employers in the region, shares an equal concern for its carbon footprint. In an effort to capture the travel behavior of the McGill population, an online travel survey was designed and administered to approximately 19,662 McGill employees and students. The survey response rate reached 25\%, which is comparable to previous surveys conducted in a university context (Páez \& Whalen, 2010). The main goal of this study is twofold: first, to propose a methodology for estimating total GHG emissions generated by the McGill population during their daily commute to the downtown campus, and secondly, to better understand who, how, and when each individual commutes to McGill. We then demonstrate the value of this information in the evaluation of a range of policies and their impact on the carbon footprint of a large employer.

This paper commences with a review of recent research in conducting travel-related GHG emission inventories, and then continues with a discussion of data used and methodology. The results summarizing the segmentation of GHG emissions among commuters are presented, 
followed by a discussion supported by a scenario-based analysis of GHG reduction opportunities for McGill commuters. Finally, this paper concludes with a presentation of policy recommendations.

\section{TRANSPORTATION GHG EMISSION INVENTORIES: RECENT EVIDENCE}

While GHG emission inventories are compiled at different scales (countries, regions, metropolitan areas, communities, and organizations) on a regular basis, their scope and breadth, in both methodology and analysis, varies dramatically. The majority of these inventories include GHG generated from various sectors, such as infrastructure, electricity, waste and transportation. Transportation is one of the most rapidly growing sources of carbon emissions (Schipper, MarieLillu, \& Gorham, 2000). In Canada, transportation GHG emissions have increased by 35\% between 1990 and 2007 (Terefe, 2010). For this reason, interest in the assessment of emission reduction targets through scenario building, particularly in the road sector, has increased. Key measures such as reducing urban vehicle kilometers traveled, increasing the share of active transportation and public transit, and increasing vehicle occupancy rates often provide the basis of scenarios developed to achieve GHG reduction targets (Stanley, Hensher, \& Loader, 2009). Recent literature highlights the utility in identifying the opportunities and limitations for such reductions through emission inventories, scenario building, and policy assessments (Hickman \& Banister, 2007).

A considerable focus in GHG emission inventories has been placed on comparisons of $\mathrm{CO}_{2}$ emissions between motorized and non-motorized trips, with particular emphasis on cycling habits (Walsh, Jakeman, Moles, \& O'Regan, 2008), and assessing the energy implications of such modal shifts (Lovelace, Beck, Watson, \& Wild, 2011). While early works have established broad correlations between urban density and energy consumed for commuting (Newman \& Kenworthy, 1988), travel-based surveys are the most effective way of highlighting the complexity of energy consumption and capturing the emissions associated with daily travel made by individuals. Ko et al. (Ko, Park, Lim, \& Hwang, 2011) used travel diary surveys to identify the largest producers of $\mathrm{CO}_{2}$ emissions in the Seoul metropolis, revealing strong associations between modal intensities and distance traveled with emitter's socioeconomic characteristics. Independent of mode of travel, location and unit of analysis, it is echoed that variables of economic and social structure significantly influence emission levels (Brand \& Boardman, 2008). The literature supports that behavioral change, which is often influenced by sociodemographic factors, must be targeted through policy in order to stabilize rising $\mathrm{CO}_{2}$ emissions (Chapman, 2007). Chapman (2007) highlights the importance of policies that change travel patterns in the short term, rather than solely focusing on the long-term impacts of technological innovation to reduce $\mathrm{CO}_{2}$ emissions.

A common approach to obtaining a comprehensive overview of the prevailing travel patterns, particularly for universities and institutions, is through detailed commuting surveys distributed to 
individuals in the academic community (as applied in Cotnoir, 2004; Cotnoir \& Chénier, 2008; Páez \& Whalen, 2010; Shannon et al., 2006, among others). However, accurate emissions calculations are largely excluded from data analysis. Alternatively, academic institutions have sought the use of pre-existing tools for computing these emissions (within the greater context of their carbon footprint), such as the Clean Air-Cool Planet Campus Carbon Calculator, the California Climate Action Registry, or the Torrie Smith Associates Emission Greenhouse Gas Strategy Software (AASHE, 2011). However, of these institutional inventories, their comprehensive nature aggregates the transportation sector (particularly commuting habits) to generalized assumptions, such as frequency, distance traveled and emission factors, as seen by inventories done by Rice University, Tulane University, and the University of Maryland (AASHE, 2011; Davey, 2002; Kwan, 1999). Evidence of detailed travel surveys exists for institutions outside of North America, such as the 2010 Travel Survey administered by the University of Edinburgh in Scotland (Buchanan, 2010).

This study contributes to the literature by providing evidence for a substantial, yet overlooked niche. An online survey was designed to capture the commuting habits of the McGill population, and was specifically constructed in a way that allowed GHG estimations to become one of the main goals of the study. Accordingly, several questions were added to the survey to help quantify emissions of commuters to McGill. The use of detailed survey responses reflect the robustness of this methodology for calculating $\mathrm{CO}_{2}$ emissions, and the alternative scenarios that are developed in the study help explore ways in which this carbon footprint can be reduced. The following section provides details about the survey design.

\section{SURVEY DESCRIPTION}

The Transportation Research at McGill (TRAM) research group, in collaboration with the McGill Sustainability Office, undertook a project beginning in December 2010 to assess the travel behaviour of McGill University students, faculty and staff. The objective of this project was not only to understand how University members commute to McGill campuses, but also how they use the various transportation services and incentives offered by the City of Montreal and McGill University as part of their travel. Another objective of the project was to quantify the environmental impact of travel to McGill and increase awareness of this impact across the McGill community.

\section{Survey Design}

A large-scale online survey was conducted through the month of March, 2011. The target population of the survey included McGill students, staff, and faculty, with the goal of capturing representative data for all types of statuses/job categories. Participants were asked to describe their last trip to McGill through a series of guided questions, using a filtering mechanism to instantly modify the series of questions based on the respondents' previous answers. For 
example, specification of vehicle type, which is useful for transportation emissions calculations, is a question that is asked only to people who use motorized vehicles in their last commute to McGill. Respondents were asked to indicate the postal code or the nearest street intersection to their place of residence while working/studying at McGill, as well as the area of campus where they spend the majority of their time. The survey also included questions regarding specific travel choices and trip "legs" (Figure 1). In addition, participants were asked to specify the train, metro or bus routes that were used if they indicated the use of public transit. Finally, to adjust for seasonality in mode choice, survey participants were asked to describe the entire sequence of their last trip to McGill and were asked to do the same in case they typically conduct a different sequence on a "nice fall day". For this purpose, commuters would provide the most recent trip sequence which we assume to describe their winter commute as well as their "typical" fall commute if it is different.

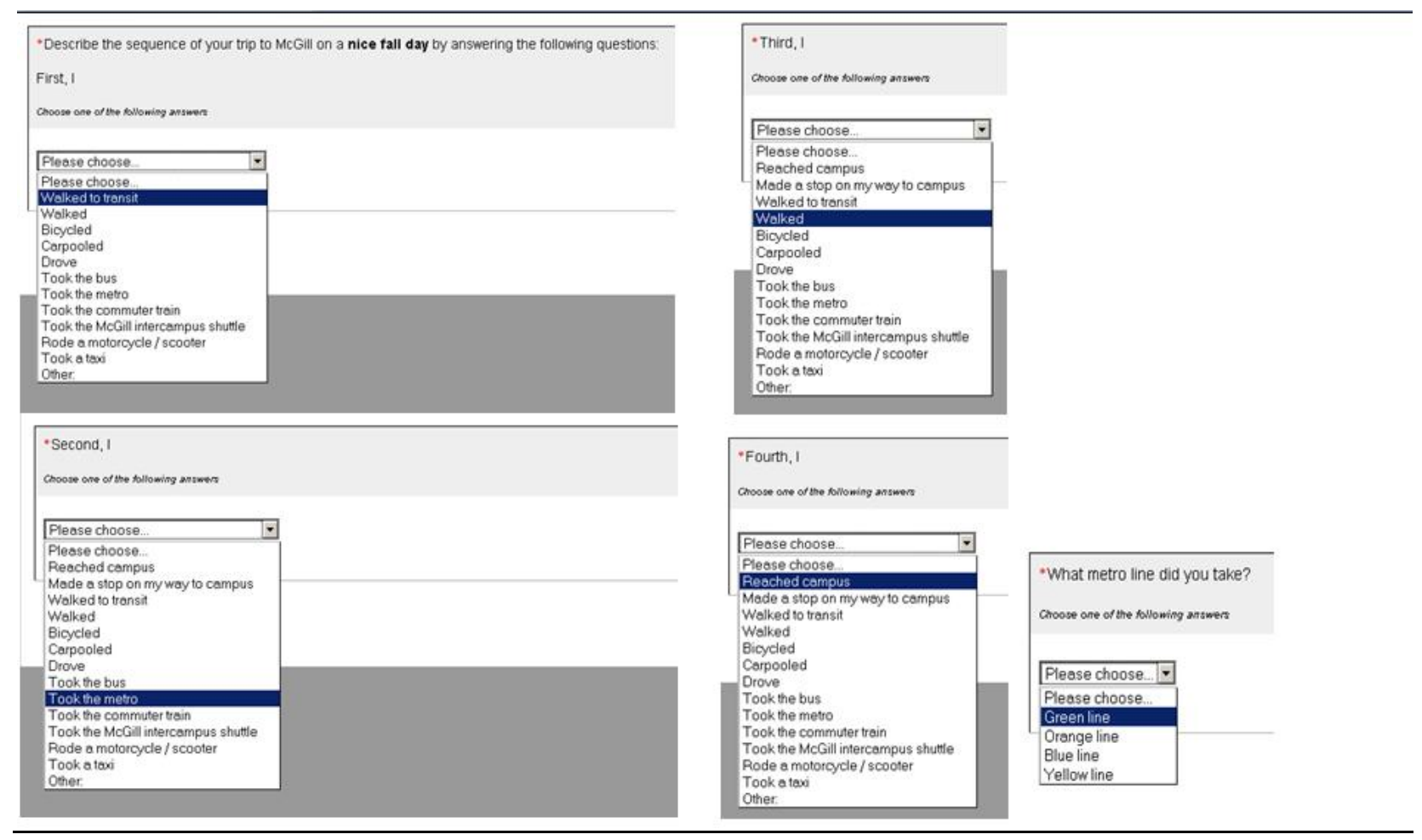

Figure 1: Screenshot of commuter sequence questions in the Web-based survey

\section{Survey Responses}

An email list of all faculty, staff and students working/studying at McGill was obtained from the Provost's Office. Email invitations were distributed to all faculty and staff that had a McGill email address $(8,493)$. For those staff members who do not have a McGill email address, such as maintenance staff, a postcard inviting them to go online and take the survey was mailed to their McGill work location. Ideally, the survey would have been distributed to the entire McGill student population, however, there were issues with overloading students with email requests, 
and therefore the number of invitations that could be sent to students was restricted to 11,000 , or approximately $30 \%$ of the McGill student population. Therefore, students were randomly selected within each borough and municipality in the Montreal Metropolitan Region, with the goal of obtaining responses from no less than $5 \%$ of the McGill student population residing in each borough or municipality.

Of the 19,662 surveys distributed among the McGill community, 5,016 responses were obtained by the closing date of the survey, yielding an overall response rate of $25.5 \%$, which is similar to the results of other comparable studies (Páez \& Whalen, 2010). Following a series of data cleaning operations, through which incomplete survey responses were removed, a total of 4,362 entries were found to be suitable for data analysis, giving rise to a sampling error of plus or minus $2 \%$ at the $99 \%$ confidence interval. Of these responses, $56 \%$ are employees (including faculty and staff), $43 \%$ are students, and $1 \%$ fall into the category of "other," including visiting students and professors.

Summary statistics concerning mode split, distances, seasonality and trip motivations were generated for the survey sample. The mode split of the sample population resulted in $16 \%$ of users commuting by motorized vehicle, $55 \%$ of users commuting by transit and the intercampus shuttle, and $29 \%$ of users cycling or walking to McGill's campuses. When combined, active transport and public transit make-up $84 \%$ of the primary mode of transportation used to travel to the McGill campus. Seasonally, users of active transport increase during the fall (from a frequency of 1,162 users in the winter to 1,774 users in the fall), with a corresponding decrease in public transit (from a frequency of 2,854 users in the winter to 2,320 users in the fall). The reduced number of individuals who take transit or drive corresponds to the augment of cycling and walking, and accounts for the increase in active transportation in the Fall.

\section{Survey responses considered for the calculation of GHG emissions}

In recognizing that the number of individuals who commute to McGill varies every day, it would be wrong to assume that the entire sample took a trip to McGill on the same day. Part-time employees, flexible student schedules, and the option to telecommute all affect the real number of daily commuters. To reflect this, the sample size was discounted to only those respondents who indicated a trip was made the day before the survey was completed. For example, if one individual finished the survey on the $10^{\text {th }}$ of March and reported his last trip to be on the $8^{\text {th }}$ of March, he was excluded from the total GHG calculations. The only exceptions were for those who completed the survey on a Sunday (or up until 9 am on Monday), in which case the last trip could have been two days prior to the completion of the survey. Therefore, survey responses considered for GHG emission calculations amounted to 3,216 entries (including all modes) thus bringing the "effective response rate" to $16 \%$. 


\section{Sampling Rate}

The color gradient in Figure 2 depicts the sampling rate, while the numbers indicated directly on the map represent the actual number of employees and students included in the sample for each borough or municipality. Overall, survey respondents provide a reasonable representation of employees and students commuting to McGill from all over the region, with the exception of a few areas. For McGill faculty and staff (Figure 2), a sampling rate of 5\% or higher was obtained for the majority of the boroughs and municipalities in the region. For McGill students (Figure 3), a sampling rate of $2 \%$ or higher was obtained for the majority of the boroughs. Beyond the distribution of the sample population in terms of status/job description and home location, no other attributes could be verified due to the limited personal data that the University agreed to disclose.

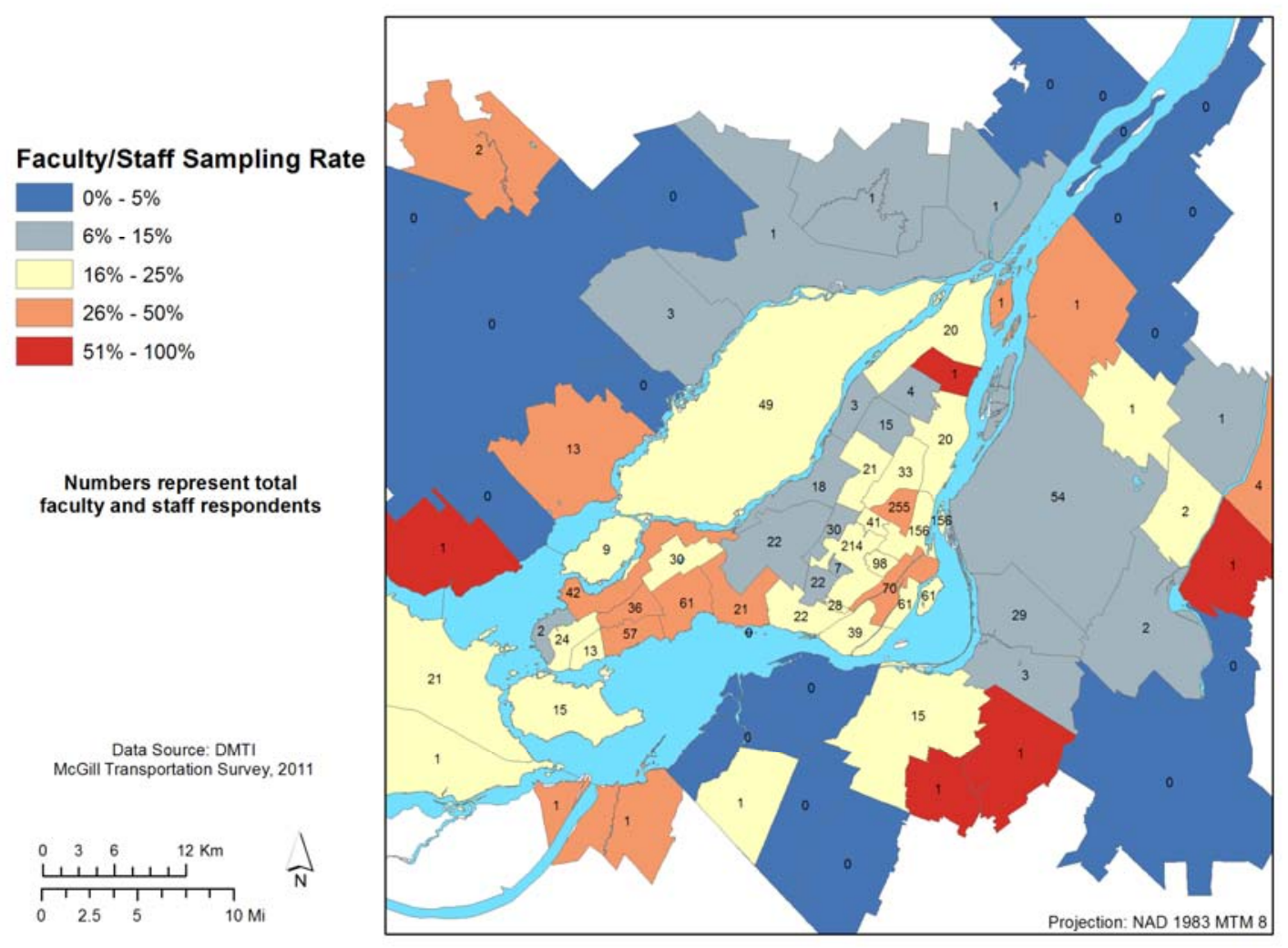

Figure 2: Sampling rate of faculty and staff by borough and municipality in the Montreal Metropolitan Region 


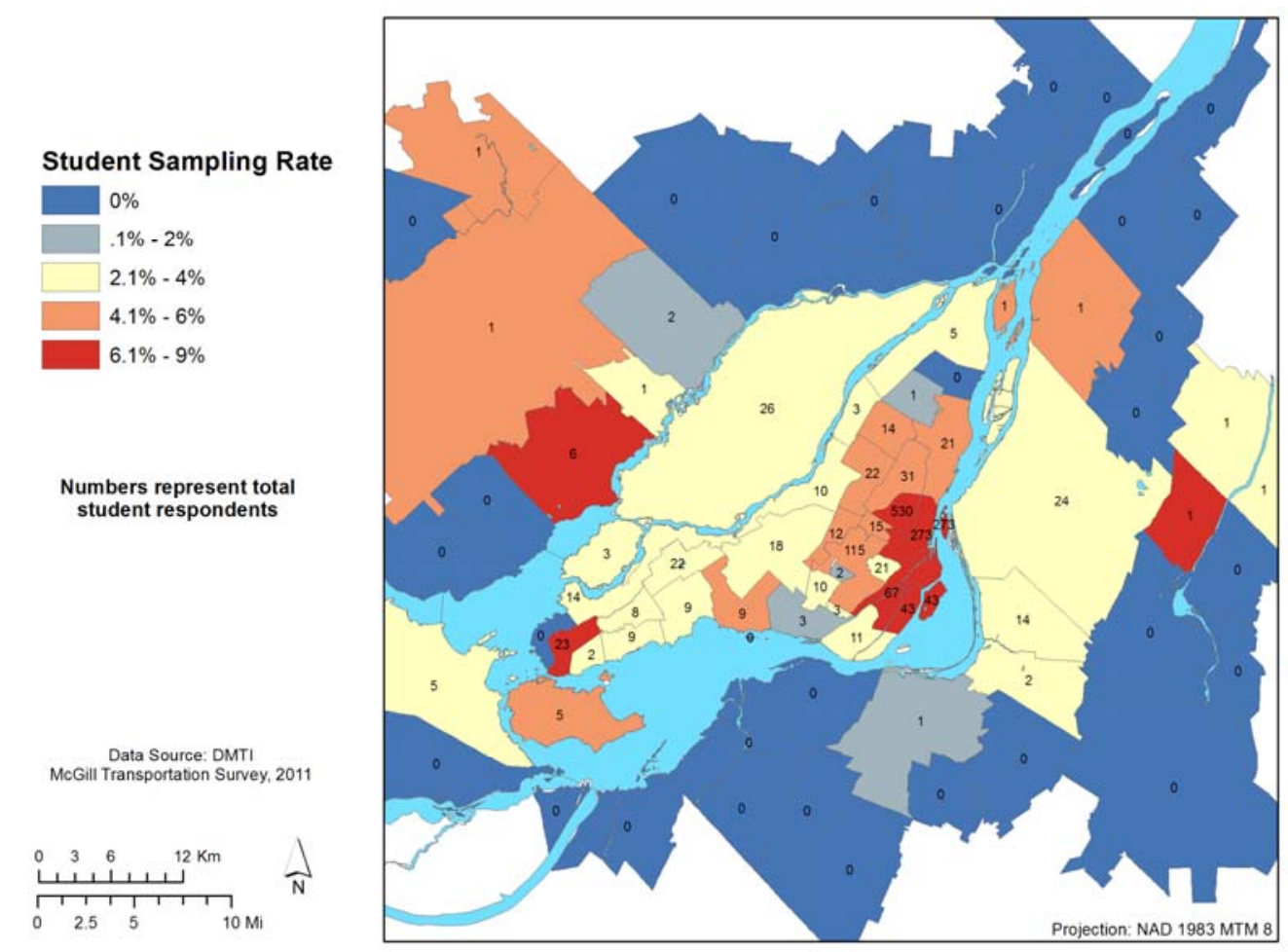

Figure 3: Sampling rate of students by borough and municipality in the Montreal Metropolitan Region

\section{STUDY METHODOLOGY}

Calculating travel-related GHG on a trip basis requires knowledge of the particular characteristics of each trip. Of the 3,216 entries included in our sample, 2,208 of these entries indicated the use of a motorized mode of transportation. The trip characteristics of these emitters include: mode and vehicle type, speed, and distance traveled. Since respondents were only asked to describe the last trip to McGill, GHG emissions are quantified only for the trip coming to the University but not for the trip back home.

\section{Distances}

For all 2,208 motorized trips included in the total emission calculations, the home postal code and destination postal code were used to determine trip distance. These were calculated using the "network analyst" feature in a geographic information systems (GIS) environment. For individuals using solely a passenger car for their commute, distances were modeled between their home location and the McGill downtown campus using the street centerline file as the base for the network. For individuals making transit trips, distances were calculated based on the length of the specified metro, train or bus line using the transit network. For individuals using a 
combination of transit and motorized vehicles (park and ride), methodologies were combined and adapted to account for distances associated with each mode of the trip. Whereas car distances are measured to the nearest transit station along the transit line that the individual reported, transit distance is measured from this point until the end of the trip along the transit network.

\section{Speeds}

Vehicle travel times were based on origin-destination travel times derived from the EMME/3 traffic assignment model calibrated and maintained by the Ministry of Transport Quebec (MTQ) for all traffic analysis zones (TAZ) in the region. Based on the trip departure time, we used the travel time matrix for the "morning peak period" or the "off-peak period". Every trip origin and destination available in the survey was assigned a TAZ to determine the average speed.

For individuals using a combination of driving and transit (park and ride), speeds were compiled for each leg of the trip where the modes differed. For the car portion of the trip, speed was derived from the travel time between the TAZ of origin and the TAZ where they boarded the first transit line. The boarding point is defined as the nearest transit stop along the reported transit line to the home location. In some cases, an individual's origin and destination fell within the same TAZ. Accordingly, travel time within a TAZ was derived based on average speed observed between the TAZs.

Meanwhile, transit travel times were derived by entering the origin (home postal code) and destination (McGill's postal code) into GoogleMaps to obtain a set of transit alternatives for every trip. These alternatives were then matched to the route that the individual reported to have used to reach the McGill campus. These matches were made by developing a java script that captured travel times along the different transit modes (metro, bus and train). Correspondingly, the speeds for each type of transit mode (metro, bus and train) are based on both the GoogleMaps transit travel times, and the average values obtained from the regional transit bodies, the Societe de Transport de Montreal (STM) and Agence Metropolitaine de Transport (AMT). While the metro and train have relatively stable speeds (40 km/hr and $80 \mathrm{~km} / \mathrm{hr}$, respectively), buses were reported to travel an average of $18 \mathrm{~km} / \mathrm{hr}$.

\section{GHG Emission Factors}

Emission Factors for GHGs were generated for each travel mode in grams of $\mathrm{CO}_{2} \mathrm{eq}$ per kilometer per passenger depending on speed and vehicle type (Table 1). For passenger vehicle users, the survey asked each individual to report the type and model year of vehicle used for the commute and the number of individuals in the vehicle, allowing the total emission of a car to be divided by the reported occupancy, where applicable. Emission factors for motor vehicles were derived from the MOVES model developed by the USEPA, and fitted with input data reflecting the Montreal conditions. MOVES was used to develop a look-up table of Emission Factors for 
light-duty gasoline vehicles (passenger cars) and light-duty gasoline trucks (mainly Sports Utility Vehicles -SUVs- and Minivans) as a function of age (up to 25 years) and average speed (4-90 $\mathrm{Km} / \mathrm{hr}$ ). These were the main vehicle types encountered in the survey. Emission Factors for passenger cars were found ranging from $180 \mathrm{~g} \mathrm{CO}_{2} \mathrm{eq} / \mathrm{Km}$.vehicle at a speed of $4 \mathrm{Km} / \mathrm{hr}$ to $650 \mathrm{~g}$ $\mathrm{CO}_{2} \mathrm{eq} / \mathrm{Km}$.vehicle at a speed around $90 \mathrm{Km} / \mathrm{hr}$ (for an average vehicle representing the vehicle age distribution of the sample). Emission Factors for SUVs were higher, varying between $230 \mathrm{~g}$ $\mathrm{CO}_{2} \mathrm{eq} / \mathrm{Km}$.vehicle and $770 \mathrm{~g} \mathrm{CO}{ }_{2} \mathrm{eq} / \mathrm{Km}$.vehicle (for an average vehicle representing the vehicle age distribution of the sample).

The Emission Factors for transit were based on the numbers reported by the regional transit authorities. The STM buses emit around 1,600 $\mathrm{g} \mathrm{CO}_{2} \mathrm{eq} / \mathrm{Km}$.vehicle with an average occupancy of 40 people in the morning, resulting in $40 \mathrm{~g} \mathrm{CO}_{2} \mathrm{eq} / \mathrm{Km}$.person. The AMT trains emit around $80 \mathrm{~g} \mathrm{CO}_{2} \mathrm{eq} / \mathrm{Km}$.person in the morning period. Meanwhile, the metro, by utilizing hydroelectric power, is reported to emit $0 \mathrm{~g} \mathrm{CO}_{2} \mathrm{eq} / \mathrm{Km}$.person. The McGill intercampus shuttle, a converted school bus, emits around 2,000 $\mathrm{g} \mathrm{CO}_{2} \mathrm{eq} / \mathrm{Km}$.person and has an average load of 40 passengers, resulting in a value of $50 \mathrm{~g} \mathrm{CO} 2 \mathrm{eq} / \mathrm{Km}$.person in the morning. Note that average per-person transit Emission Factors are based on morning peak-period occupancy rates. In the base-case scenario, these Emission Factors are acceptable because they are based on observed occupancy rates. However, as discussed in the Emission Scenarios section, these averages are expected to become lower as transit ridership increases. Marginal emissions were not taken into account; instead, the same average emissions per person were assumed. This limitation is discussed in the Concluding Section.

Table 1: Emission Factors for Motorized Vehicles and Transit

\begin{tabular}{cccc}
\hline Mode Type & $\begin{array}{c}\text { Speed } \\
\mathbf{( K m} / \mathbf{h r})\end{array}$ & $\begin{array}{c}\text { Emission Factor } \\
(\mathbf{g} / \mathbf{K m} / \mathbf{p e r s o n})\end{array}$ & Source \\
\hline Passenger Car & $<=4-90$ & $180-650^{*}$ & MOVES \\
SUV & $<=4-90$ & $230-770^{*}$ & MOVES \\
Metro & 40 & 0 & STM \\
Bus & 18 & 40 & STM \\
Train & 80 & 80 & AMT \\
McGill Shuttle & 40 & 50 & MOVES \\
* Assuming single occupancy & &
\end{tabular}

\section{Sampling Weights}

Since the sample size of the survey does not correspond with the real number of individuals commuting to McGill, the number of respondents was expanded to represent the entire population. During the survey process, McGill provided the research team with the postal code associated with each student (graduate and undergraduate) and employee (faculty and staff). In the survey, students and employees were asked to report their home postal code, which was 
linked in GIS to the borough where they reside. Sampling weights were derived by dividing the real number of students and employees in each borough by the number of students and employees residing in the same borough within our sample. For this purpose, weights were generated based on status/job category (faculty, staff, graduate, and undergraduate student), affiliated department, and home location (Table 2). No other personal attributes were provided by McGill. The generated weights are therefore based on a limited set of individual characteristics. Our sample over-represents faculty and under-represents students due to the limit on the number of students who could be invited. $\mathrm{CO}_{2} \mathrm{eq}$ totals were computed based on the sampling weights of these individuals commuting from their borough to estimate a total carbon footprint for the entire McGill community.

Table 2: Range of Sampling Weights

\begin{tabular}{cccc}
\hline Status/Job category & Average & Minimum & Maximum \\
\hline Employee & 5.58 & 1 & 24 \\
Students & 12.48 & 8.5 & 43.5 \\
\hline
\end{tabular}

For both students and employees, the boroughs of Plateau Mont-Royal, Ville-Marie, and Cotesdes-Neiges/Notre-dames-de-Graces have the highest density of survey respondents. The sampling weights of these boroughs for employees are 3.25, 4.87 and 6.07 respectively. In contrast, students have a sampling weight 9.65, 12.36 and 12.46 for each of these boroughs respectively. The geographic distribution of the range of these expansion factors, based on the sample rates of each borough, is represented in Figure 2.

\section{RESUlts AND Discussion}

Recall that survey responses were gathered in March, which is a typical winter month in Montreal. As described in the Survey Design section, respondents were asked to fill two different trip sequences in case their fall commute is different from their March commute. Figure 4 confirms an increase in active transport users in the fall among both students and employees, with a corresponding decrease in transit. An increase in public transit users across statuses occurs in the winter, where other options can be limited by weather. Automobile rates, though marginally higher in the winter for employees compared to students, stays relatively constant among both groups, suggesting that those who drive may have limited alternative options regardless of season. Therefore, the reduced numbers of students and employees that take transit in the fall mostly corresponds to the augment of cycling and walking. 


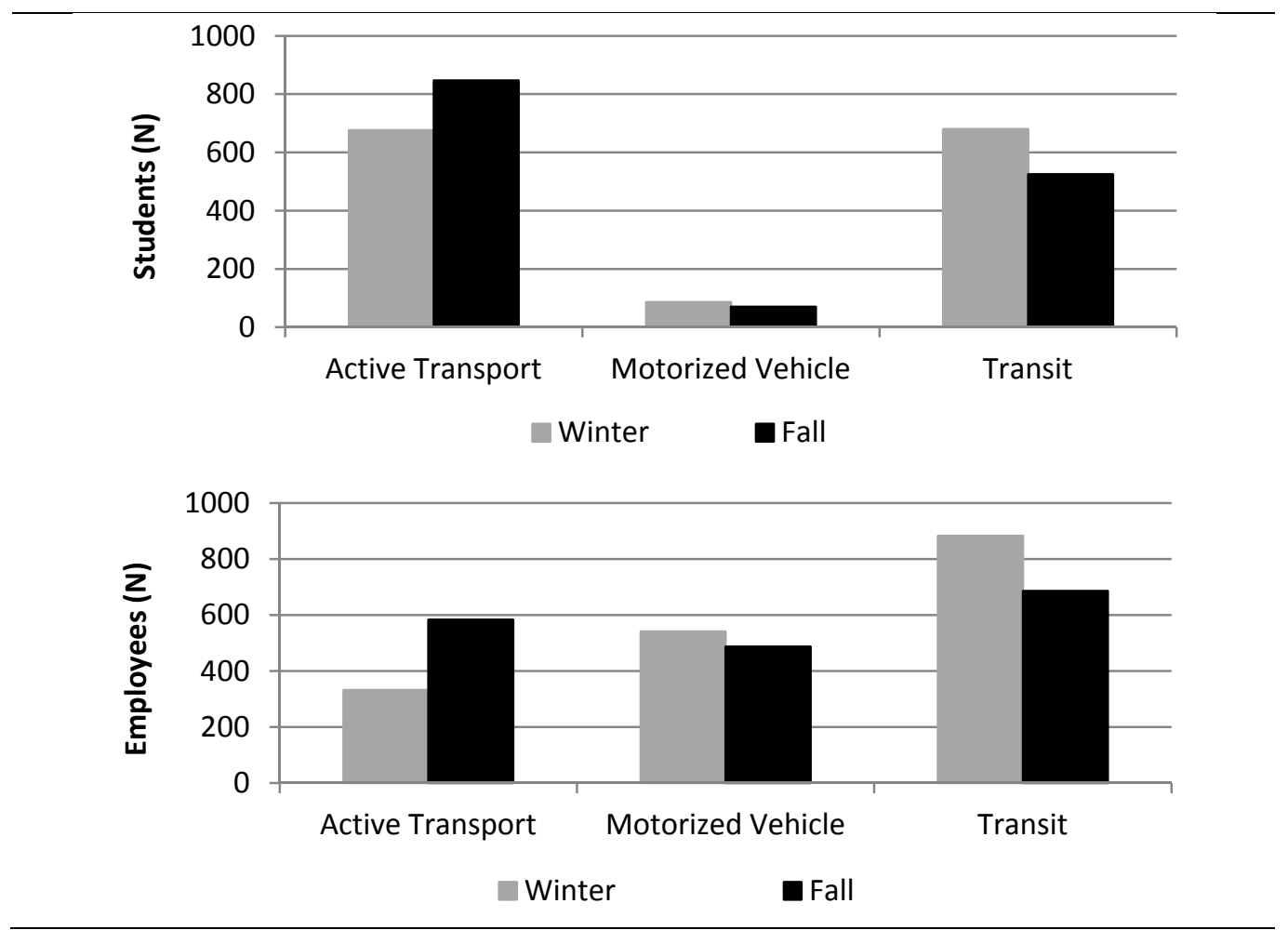

Figure 4: Mode share for Student/Employee by season

\section{Who is emitting?}

The goal of this section is to understand who is emitting the most among the different groups commuting to McGill's downtown campus to help in generating policies that can target the highest GHG emitters. Accordingly, the values used in this section are derived directly from the survey sample, without applying sampling weights. When generating these averages and figures throughout this section, all 3,216 trips, which comprise walkers and cyclists, are included.

\section{Gender}

While the highest emitters, on average, tend to be among employees, further variables can be used to describe these individuals. A male faculty or staff contributes an average of $1679 \mathrm{~g}$ $\mathrm{CO}_{2} \mathrm{eq} /$ person.trip ( $\mathrm{SE}=90$ ) when commuting to McGill's downtown campus, while a female would contribute $1721 \mathrm{~g} \mathrm{CO}_{2} \mathrm{eq} /$ person.trip ( $\mathrm{SE}=74$ ). Among the students, however, a female contributes $538 \mathrm{~g} \mathrm{CO}_{2} \mathrm{eq} /$ person.trip ( $\mathrm{SE}=49$ ) and a male contributes 412 g CO${ }_{2} \mathrm{eq} /$ person.trip (SE = 52). When comparing GHG emissions in winter for male and female respondents (both students and staff), an independent-samples t-test reveals no statistical difference between these two groups. 


\section{Age}

Figure 5 shows the age distribution for McGill's employees and students on the $X$-axis and the average GHG emitted by individuals in this age group on the Y-axis. A secondary Y-axis shows the number of respondents from the McGill survey who fall in this age category. The average age of the highest emitters falls into the same age category for both employees and students. Individuals between the ages of 41-50 emit an average of 2,012 $\mathrm{g} \mathrm{CO}_{2} \mathrm{eq} /$ person.trip ( $\mathrm{SE}=$ 506.4) and 2,142 $\mathrm{g} \mathrm{CO}_{2} \mathrm{eq} /$ person.trip ( $\mathrm{SE}=125.5$ ) for students and employees, respectively. However, only 29 students fall into this age bracket, compared to the 497 employees aged 41-50 in our sample. The majority of students fall between the ages of 21-30 (895 respondents), yet a student commuting to McGill's downtown campus in this age category only contributes an average amount of $416 \mathrm{~g} \mathrm{CO}_{2}$ eq/person.trip ( $\mathrm{SE}=38$ ).

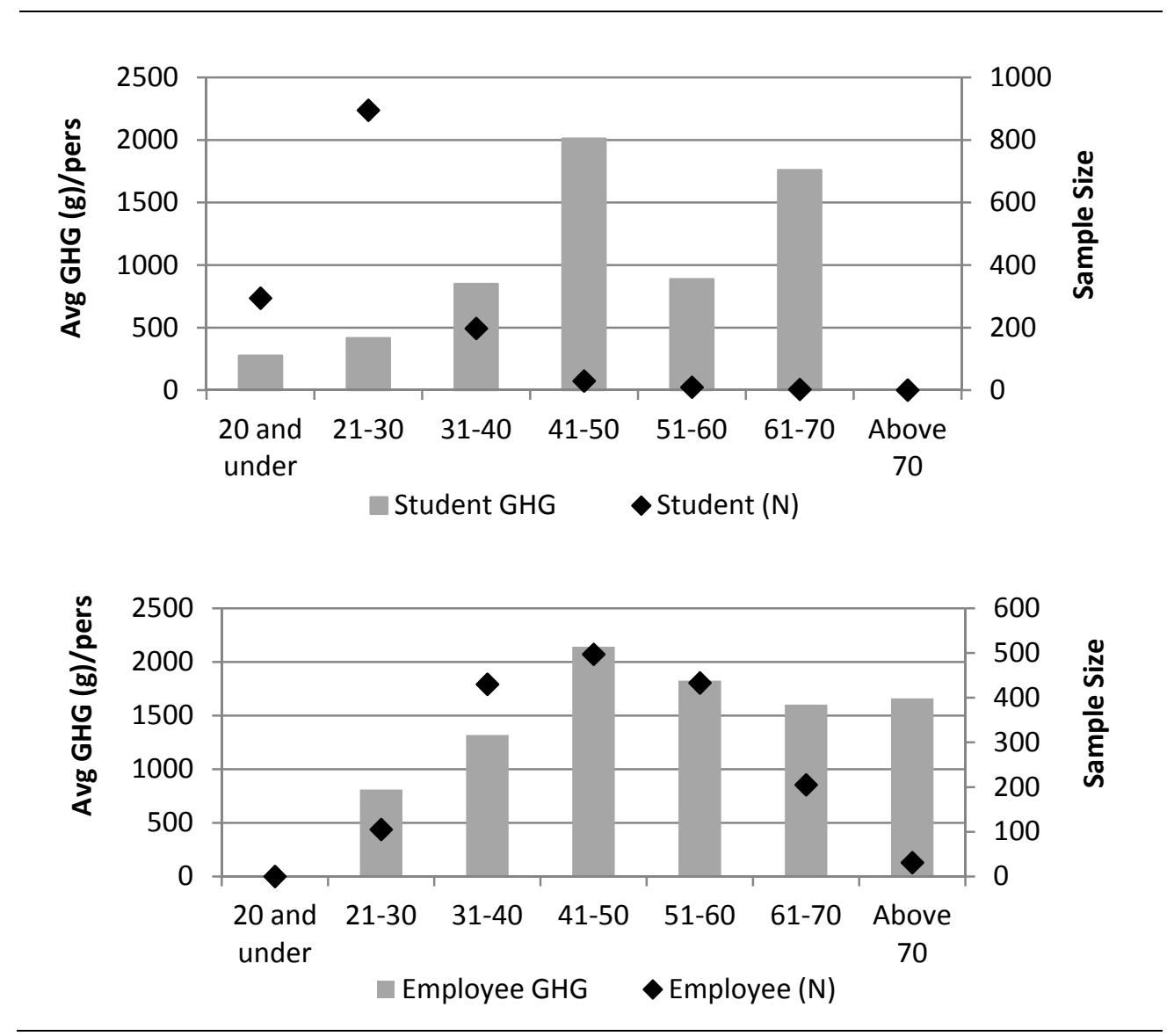

Figure 5: Average GHG for Employee/Student by age

A one-way ANOVA test was conducted to compare GHG emissions in winter between the different age groups (including both employees and students). Emissions differed significantly between all seven age groups $\left(\mathrm{F}\left(6,3138^{1}\right)=62.805, \mathrm{p}<0.001\right)$. The difference in emissions

171 of the 3,216 respondents were removed for this test, as their age was undisclosed. 
between ages can be best attributed to home location, which can have a strong influence over mode choice. The majority of students that are below the age of 30 reside closer to the downtown campus, lending to higher rates of active transport and public transit. As age increases among employees and students, distance increases between campus and their home location, which lends to higher emitting modes.

\section{Status / Job category}

On average, an employee emits around 1,716 $\mathrm{g} \mathrm{CO}_{2} \mathrm{eq}(\mathrm{SE}=57)$ and a student emits $491 \mathrm{~g}$ $\mathrm{CO}_{2} \mathrm{eq}(\mathrm{SE}=36)$ on a typical winter trip. An independent-samples t-test revealed a significant difference in average GHG emissions for employees $(p<0.001)$. Out of all employees, security maintenance personnel have the greatest average emissions of 2,321 $\mathrm{g} \mathrm{CO}_{2} \mathrm{eq} /$ person.trip $(\mathrm{SE}=$ 307). The second two groups that have the highest emissions per commuter are adjunct faculty and continuing education students, with $\mathrm{CO}_{2}$ emissions around 1,472 (SE = 437) and 1,661 (SE = 328) $\mathrm{g} \mathrm{CO}_{2} \mathrm{eq} /$ person.trip respectively. Post-doctoral students contribute around $422 \mathrm{~g}$ $\mathrm{CO}_{2} \mathrm{eq} /$ person.trip ( $\mathrm{SE}=135$ ), whereas undergraduate and graduate students contribute around 409 (SE = 41) and 477 (SE = 62) g $\mathrm{CO}_{2}$ eq/person.trip respectively. The higher contribution of emissions by faculty and staff may be explained by the larger share of users who park and ride, or use motorized vehicles. The difference for these emissions can also be further attributed to home location, as faculty and staff generally travel greater distances by higher emitting modes.

\section{How are they emitting? Mode choice}

Figure 6 shows the mode split for McGill's employees and students on the X-axis and the average GHG emitted by individuals using this particular mode on the Y-axis. A secondary Yaxis is included to show the number of respondents from the McGill survey who fall into each mode of transport. The average GHG per person based on mode split follows a similar pattern for both employees and students. As expected, drivers emit the most $\mathrm{CO}_{2}$, and transit users emit the least. With average GHG emissions that are almost comparable to drivers, park and ride individuals heavily outweigh their savings in emissions by taking transit with the use of their car to access transit. This difference in savings is particularly stark, as transit emits significantly less than any other mode: $751 \mathrm{~g} \mathrm{CO}_{2} \mathrm{eq} /$ person.trip ( $\mathrm{SE}=48$ ) and $308 \mathrm{~g} \mathrm{CO}_{2} \mathrm{eq} /$ person.trip ( $\mathrm{SE}=28$ ) for employees and students, respectively. McGill operates a shuttle bus between its two campuses, and several students and employees that reside near one of the two campuses use the McGill shuttle to commute to the other campus. The Macdonald campus, located at the tip of the island of Montreal, is less than $40 \mathrm{~km}$ away from the downtown core. The shuttle bus in operation is an old retrofitted school bus. Students are far more likely to use the service, as the use of the intercampus shuttle is severely limited to faculty and staff. Note that the average trip emissions associated with the use of the shuttle include the GHG emitted by all modes used to reach the departure points for the shuttle. In this case, we observe that students are more likely to 
use a motorized mode of transportation to access the shuttle, which explains the larger quantity of GHG produced by students on the shuttle, as compared to employees utilizing this service.

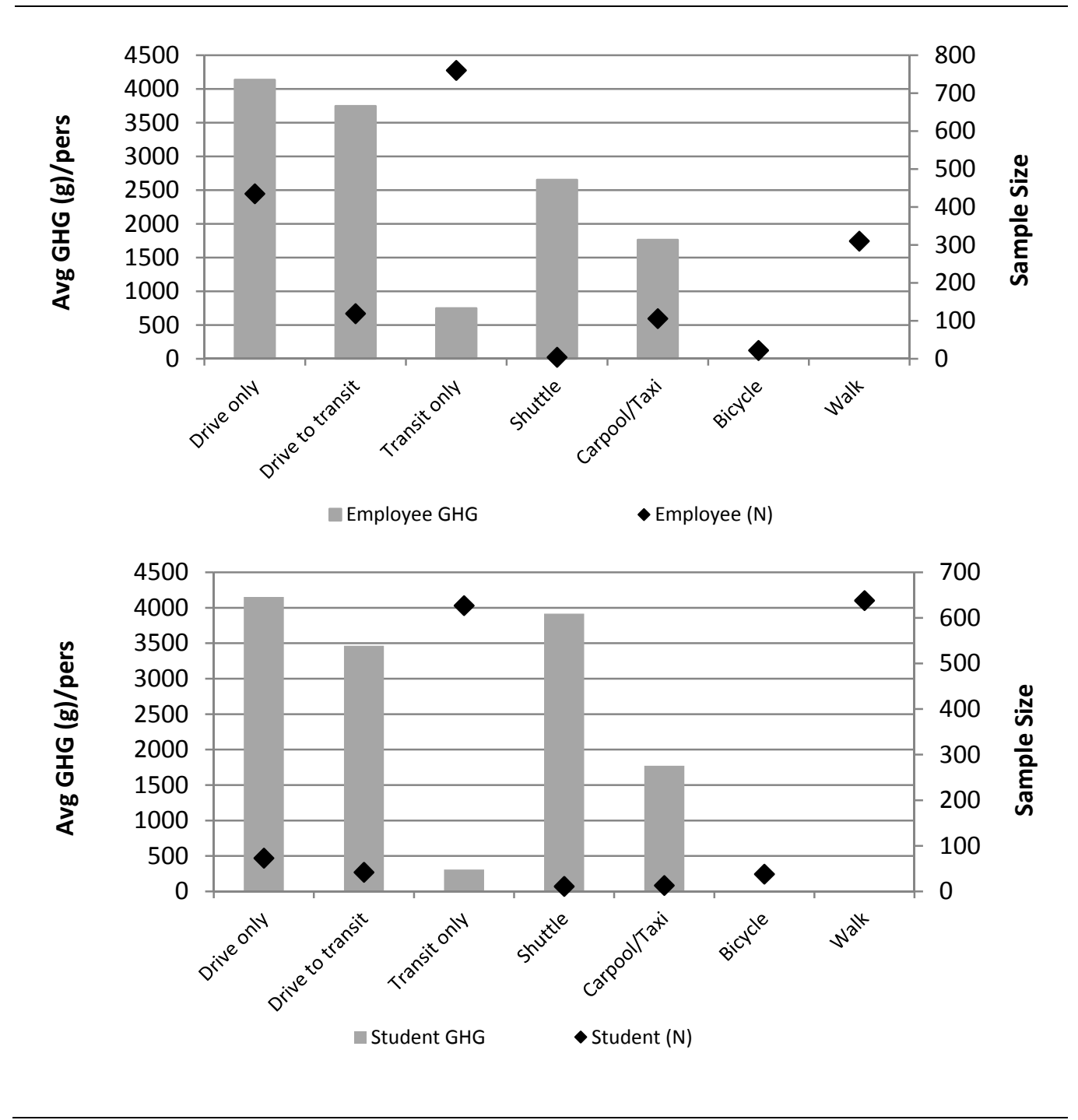

Figure 6: Average GHG for Employee/Student by mode split

\section{When are they emitting?}

\section{Emissions by season}

We estimate that on a single winter day, commuters to McGill's downtown campus generate around 31.1 tons of $\mathrm{CO}_{2} \mathrm{eq}$ on their travel to McGill. During the fall, this amount decreases to 29.5 tons. These values can be further divided between types of commuters: during the winter season, faculty and staff generate $16,230 \mathrm{~kg} \mathrm{CO} 2 \mathrm{eq}$, while students generate $14,790 \mathrm{~kg} \mathrm{CO}_{2} \mathrm{eq}$. For a commute during the fall, these numbers shift to 15,305 $\mathrm{kg} \mathrm{CO}_{2} \mathrm{eq}$ for faculty and staff, and $14,098 \mathrm{~kg} \mathrm{CO}$ eq for students. The difference for students is less than 1 ton $(692,199 \mathrm{~g})$ between 
seasons. Meanwhile, faculty and staff see a larger difference of nearly 1 ton (925,374 g) between seasons.

\section{Emissions by season and mode choice}

Based on expanded numbers, the variation of emissions by season can be further dissected to analyze the differences in mode choice among students and faculty/staff. As shown in Table 3, all emissions are lower in the fall compared to the winter season. The most notable shift is in the difference of $\mathrm{CO}_{2} \mathrm{eq}$ emitted from employees who choose a motorized vehicle for their commute. Winter $\mathrm{CO}_{2}$ emissions from this mode increase by over 0.5 tons. Meanwhile, a shift in transit emissions is only marginal for employees.

For students, the largest difference in $\mathrm{CO}_{2} \mathrm{eq}$ emissions is for those who primarily drive to McGill, closely followed by those who use a combination of transit and motorized vehicles. The seasonality of these emissions can also be observed spatially. Figure 6 shows the percentage change in the total $\mathrm{CO}_{2}$ emitted from commuters to McGill's downtown campus from different boroughs, comparing winter to fall seasons. It is clear that the largest change in emissions occurs on the island of Montreal, while commuters coming from the far suburbs generally do not deviate from their typical mode, resulting in a contribution of the same amount of GHG emissions over the year.

Table 3: Seasonal emissions among employees and students by mode choice

\begin{tabular}{lccccc}
\hline Employees & Transit only & Drive only & Drive to transit & Carpool/Taxi & Shuttle \\
Expanded GHG Winter (t) & 2.78 & 10.00 & 2.29 & 1.14 & 0.02 \\
Expanded GHG Fall (t) & 2.63 & 9.49 & 2.10 & 1.05 & 0.18 \\
\hline Students & Transit only & Drive only & Drive to transit & Carpool/Taxi & Shuttle \\
Expanded GHG Winter (t) & 4.40 & 5.45 & 3.60 & 0.61 & 0.73 \\
Expanded GHG Fall (t) & 4.24 & 5.25 & 3.41 & 0.57 & 0.62 \\
\hline
\end{tabular}




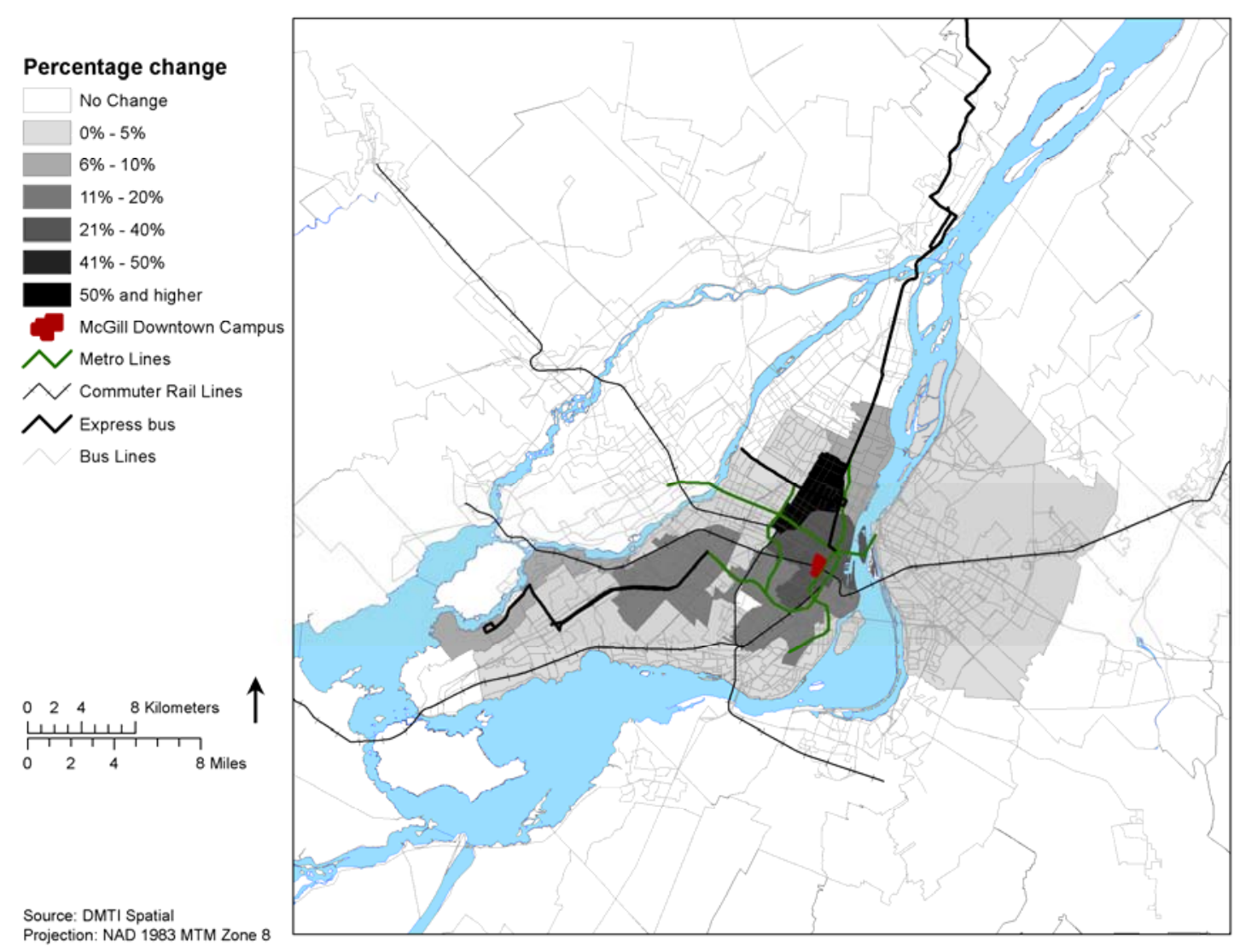

Figure 6: Percentage changes in seasonal $\mathrm{CO}_{2}$ emissions from commuters to McGill’s Downtown campus from different boroughs

\section{Emission scenarios}

In this section, we present five alternative scenarios that can provide insight into potential policy options that could help reduce the community's carbon footprint. These scenarios are based on specific information collected by the survey to determine the viability of a mode shift among certain groups of individuals in reducing their GHG emissions.

Base Case: Represents the total amount of GHG that McGill commuters emit on a typical winter day when commuting to the downtown campus, which is estimated at 31.13 tons of $\mathrm{CO}_{2} \mathrm{eq}$. All further scenarios are compared against this total.

Scenario 1: Illustrates the potential emissions if all drivers, who indicated that they took transit at least once to reach McGill in the past year, switched to transit for their commute. These typical drivers could be seen as irregular transit users, indicating that a transit option is available, whether or not the driver makes use of it. Of those who switch, 347 are employees and 72 are students, with a bell curved age distribution peaking at a frequency of 124 individuals 
between the ages of 41 and 50 . This scenario totals 24.51 tons of $\mathrm{CO}_{2}$, or $78 \%$ of the base case (Figure 7).

Scenario 2: Represents viability, rather than irregularity. Viability is defined by a commute that falls within a threshold of travel time that is reasonable enough to convince individuals to switch modes. First, GIS was used to model every alternative trip (car, transit, cycling, and walking) for each individual, regardless of their original mode. To determine the threshold for a switch to transit, the ratio of the real transit time of every transit user over their modeled driving time was 1.3, indicating that a transit user's trip is on average $30 \%$ longer than a driver's trip. While a $30 \%$ longer trip is ambitious, a $20 \%$ longer trip is a more conservative threshold for encouraging this mode shift. A threshold was also determined for the viability of switching to active transportation: if an individual could reach campus with a 15 minute bicycle ride or a 20 minute walk from their home location, active transportation was considered feasible. Thus, Scenario 2 represents a shift towards modes that would either emit no $\mathrm{CO}_{2}$, or emit less $\mathrm{CO}_{2}$ than their original trip. Of those who switch, 368 are employees and 230 are students, with an age distribution peaking at an average frequency of 138 individuals between the ages of 21 and 50 . This scenario totals 26.2 tons of $\mathrm{CO}_{2}$, or $84 \%$ of the base case (Figure 7).

Scenario 3: A combination of the opportunities from Scenario 1 (irregularity) and Scenario 2 (viability) are grouped together to represent a more comprehensive mode shift. This means all drivers who are irregular transit users switch to transit, and all other individuals switch to the next best viable alternative, whether that means drivers take transit or use active transportation, and transit users switch to active transportation, wherever it is feasible. Of those who switch, 597 are employees and 268 are students, with two peaks in age distribution: one with a frequency 202 individuals between the ages of 21 and 30, and another with a frequency of 193 individuals in the range 41-50. This scenario totals 21.74 tons of $\mathrm{CO}_{2} \mathrm{eq}$, or $69.84 \%$ of the base case (Figure 7). Figure 8 illustrates the spatial distribution of the percentage decrease (compared to the base case) in total $\mathrm{CO}_{2} \mathrm{eq}$ emitted by commuters from every borough under this scenario.

Scenario 4: This scenario contrasts Scenario 3 by offering the worst outcome. This scenario assumes that if all survey respondents indicated they used a vehicle to commute from their home location to McGill's downtown campus in the past year, they could switch to this mode. These individuals would be irregular drivers who become regular drivers. Of those who switch, 464 are employees and 236 are students, with an age distribution peaking at a frequency of 194 individuals in the range 21-30. This scenario would amount to 52.41 tons $\mathrm{CO}_{2} \mathrm{eq}$, or $68 \%$ more emissions than the base case (Figure 7).

Scenario 5: It must be recognized that the number of individuals who commute to McGill varies by day, implying that we cannot assume the entire sample commuted to campus on the same day. Yet if this was the case, and all McGill downtown campus commuters were required to be 
present on campus, emissions would amount to 40.57 tons $\mathrm{CO}_{2} \mathrm{eq}$, or $30 \%$ more emissions than the base case (Figure 7). This scenario highlights the importance of flexibility in a work schedule, and considers the choice to work from home as a valuable opportunity that should be recognized by the University. While the option to telecommute is available to most of the McGill community; only $22 \%$ of respondents indicated they actually did telecommute regularly.

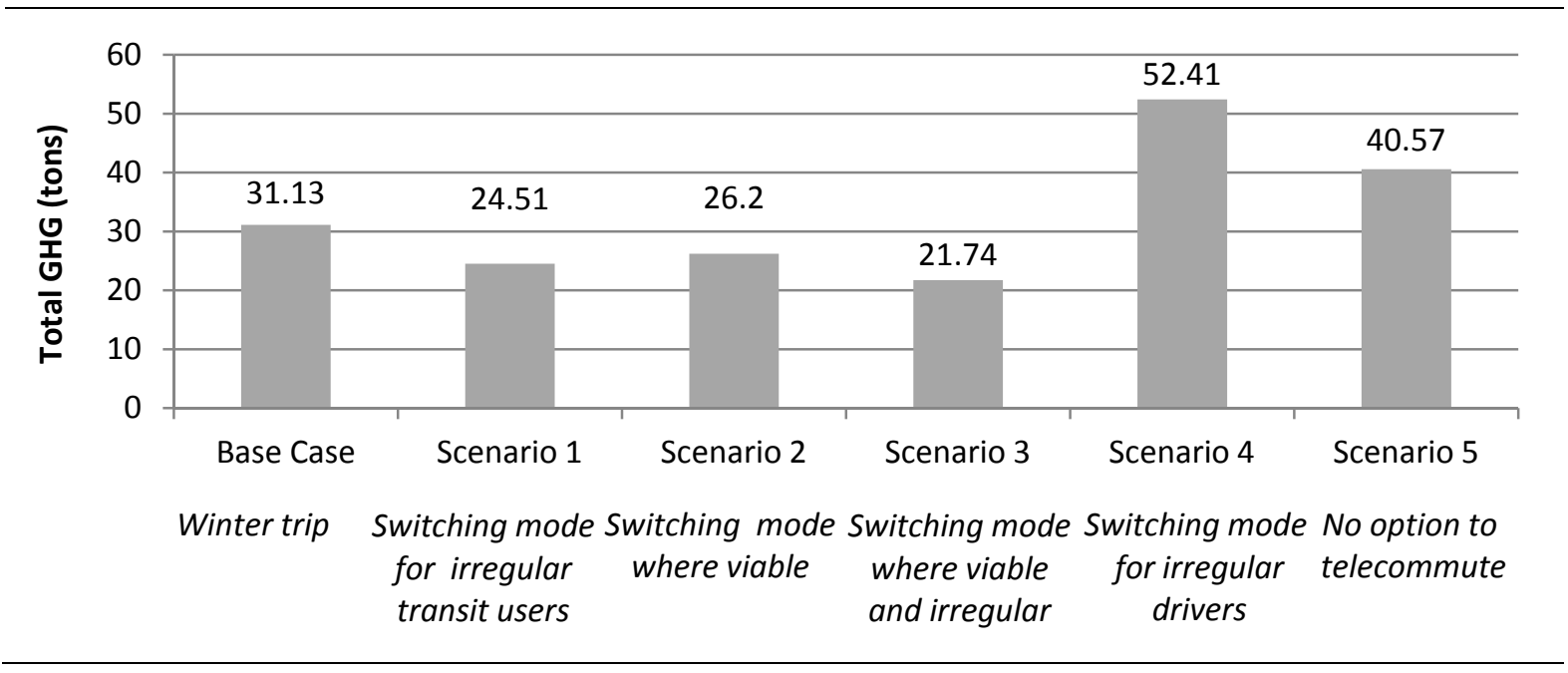

Figure 7: Total GHG (tons) by Scenario

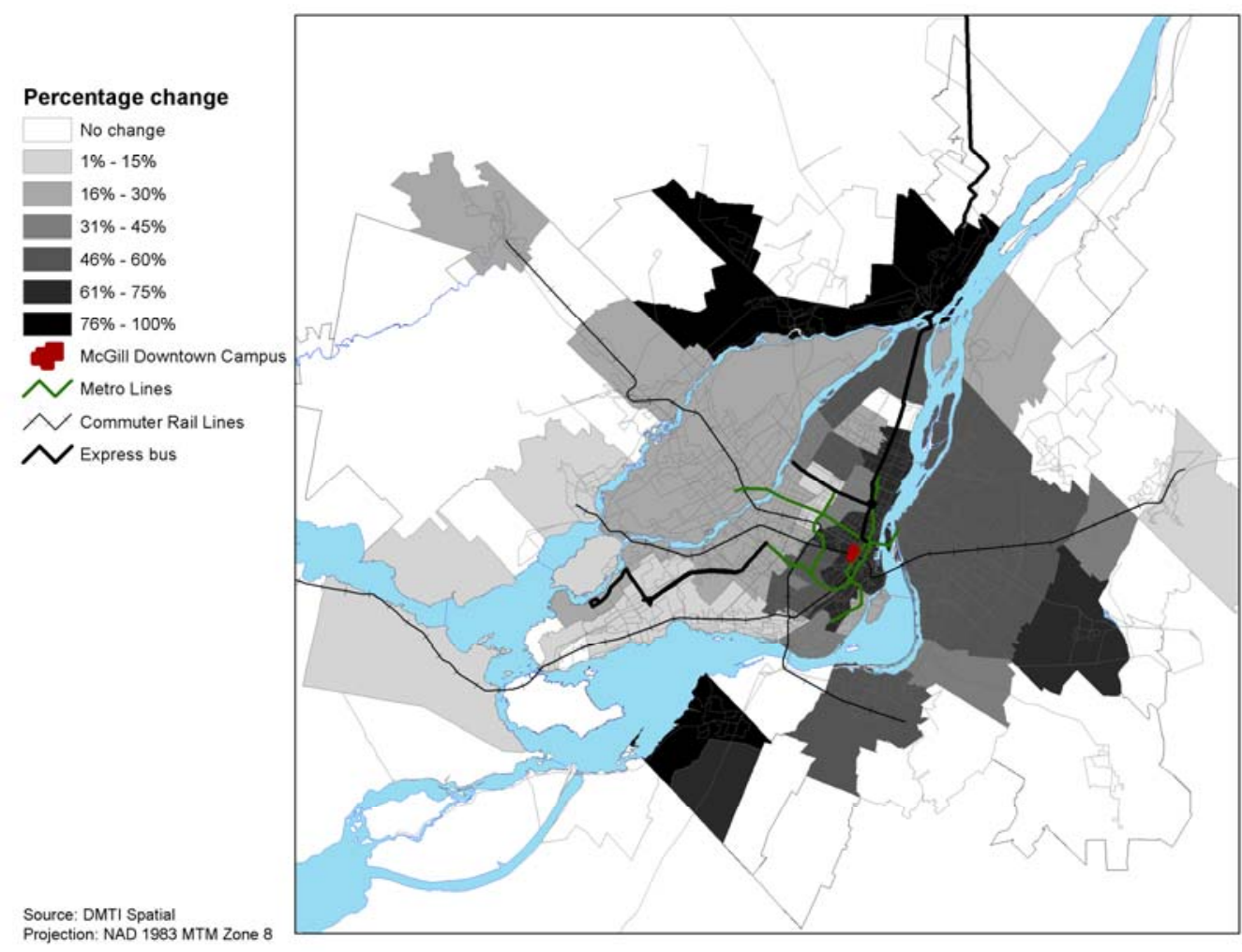

Figure 8: Percent change of emissions from Base Case to Scenario 3 (switching mode where viable and irregular) 


\section{CONCLUSION AND Limitations}

This study first set out to calculate the GHG emissions generated by individuals commuting to McGill's downtown campus. For this purpose, a travel survey was administered to a large number of faculty, staff, and students within the McGill community. The survey captured information on each trip leg including mode, vehicle type and age, and specific transit line. In addition, participants' status/job category, gender, age, and residential location were captured. Seasonality was also addressed by asking participants to describe their commute both in winter (the time when the survey was administered) and in the Fall. The survey revealed lower emissions in the Fall, mostly due to an increase in active transportation. Suburban commuters showed the most stable emissions over the two seasons due to their lower predisposition to switch transport mode. Faculty and staff were found to be responsible for significantly higher per person emissions than students. Transit emissions were lowest but emissions from park-and-ride trips were much higher indicating that savings in emissions achieved by taking transit can be quickly offset when driving (especially single occupancy vehicle) becomes part of the trip chain. Scenarios were developed based on the analysis of the survey, and their implications are unique: they entail situations that are possible and not necessarily probable or planned. Nonetheless, the pragmatism of these scenarios is reflected in the calculations made for every individual using all variations of mode split. Switching individuals from one mode to another was done by a careful evaluation of the opportunities present in the viability and irregularity of mode options. In addition, an alternative was modeled to reflect the importance of flexibility in a work schedule, particularly for large employers like McGill: if the entire community had to travel to the downtown campus every day the total GHG emissions for the commute to McGill would be $168 \%$ the base case emissions. While a car sharing or lift sharing scenario was not explicitly modeled due to the lack of information on the trip back from campus, it is important to note that the information provided by participants on each trip leg would allow for potential "ride matching”.

The estimation of GHG emissions for all commuting trips is inextricably linked with a range of limitations. While these limitations are not expected to influence the main conclusions of this research, they do however affect the GHG estimates for different sub-groups as well as the total GHG estimates for the community. Our methodology estimates exhaust GHG emissions only and therefore does not account for cold starts therefore underestimating car emissions. Our emission factors are average-speed based and hence do not take into account the effects of acceleration, deceleration, and idling on total emissions. While methods for simulating vehicle and bus emissions over the entire drive-cycle are already established, their adoption in the context of this study would require the use of a multi-modal dynamic traffic assignment model at the level of the region; which is not-available at this stage. While emissions were calculated in the winter and fall based on respondent trip chains, emission factors and occupancy rates (especially on transit) were not varied. Instead, average values were used. While temperature effects on GHG emission factors are available in the literature and expected to slightly increase 
winter emissions; occupancy rates (on transit) are expected to lead to a decrease in winter emissions. Indeed, as observed in the survey, transit ridership increases in the winter thus potentially reducing average emissions per person. In fact, a main limitation of this study is associated with the use of average rather than marginal transit emissions. These were based on average yearly occupancy. In addition, when expanding GHG emissions from the sample to the total population, expansion factors were developed based on status/job description, affiliated faculty, and residential location. We recognize this as a limitation but due to the limited availability of other information, it was not possible to base the expansion factors on a wider array of individual attributes. Note however that expansion factors only play a role in the evaluation of total GHG emissions, a relatively minor objective of this study compared with exploring the effects of personal attributes on commuting-related GHG emissions. Finally, note that the estimation of yearly GHG emissions for the entire community would involve more than a direct extrapolation of winter and fall values especially with declining student population in the summer. However, as stated previously, the analysis of individual-level GHG emissions and opportunities for "greener" travel remain the main objectives of this study.

\section{ACKNOWLEDGEMENTS}

We would like to thank the McGill Office of Sustainability and McGill Campus and Space Planning for their feedback and guidance at various stages of this project. We would also like to thank Daniel Schwartz, from IT customer services, for his assistance in developing the online survey and managing the distribution of the survey to the McGill community. Thanks to Naveen Eluru, Jacob Mason and Cynthia Jacques, for their help throughout the survey design process. We would also like to thank Guillaume Barreau for modeling the transit trips to McGill in Google maps. Finally, we express our gratitude to the McGill sustainability projects fund for providing funding for this project.

\section{REFERENCES}

AASHE. (2011). Campus Greenhouse Gas Emissions Inventories. from http://www.aashe.org/resources/campus-greenhouse-gas-emissions-inventories

Brand, C., \& Boardman, B. (2008). Taming of the few - the unequal distribution of greenhouse gas emissions from personal travel in the UK. Energy Policy, 36, 224-238.

Buchanan, C. (2010). The University of Edinburgh Travel Survey 2010. University of Edinburgh.

Chapman, L. (2007). Transport and climate change: a review. Journal of Transport Geography, 15(5).

Cotnoir, P. (2004). Attitudes and practices in commuting by McGill University students and staff: Survey Report. Montreal, Canada: McGill University. 
Cotnoir, P., \& Chénier, A. (2008). Rapport d'enquête : Attitudes et pratiques en déplacement pendulaire des étudiants et du personnel de l'Université Concordia. Montreal, Canada: Concordia University.

Davey, L. a. K., Shelley. (2002). Tulane University Greenhouse Gas Inventory. Tulane University.

Division du developpement des transports. (2008). Montreal Transportation Plan -Ville de Montreal. Montreal, Canada: Service des infrastructures, transport et environnement, Direction des transports, Division du developpement des transports.

Gouvernement du Quebec. (2008). 2006-2012 Climate Change Action Plan. Quebec, Canada: Développement durable, Environnement et Parcs Québec.

Hickman, R., \& Banister, D. (2007). Looking over the horizon: Transport and reduced CO2 emissions in the UK by 2030. Transport Policy, 14(5).

International Transport Forum. (2008). Greehouse Gas Reduction Strategies in the Transport Sector.

Ko, J., Park, D., Lim, H., \& Hwang, I. (2011). Who produces the most CO2 emissions for trips in the Seoul metropolis area? Transportation Research Part D(16), 358-364.

Kwan, N., Martindill A., and Penumalli P. (1999). University 303: The Impact of CO2. Rice University.

Lovelace, R., Beck, S., Watson, M., \& Wild, A. (2011). Assessing the energy implications of replacing car trips with bicycle trips in Sheffield, UK. Energy Policy, 39, 2075-2087.

Newman, P., \& Kenworthy, J. (1988). The transport energy trade-off: Fuel-efficient traffic versus fuel-efficient cities. Transportation Research Part A: General, 22(3), 163-174.

Páez, A., \& Whalen, K. (2010). Enjoyment of commute: A comparison of different transportation modes. Transportation Research Part A(44), 537-549.

Schipper, L., Marie-Lillu, C., \& Gorham, R. (2000). Flexing the link between transport and greenhouse gas emissions. Paris, France: International Energy Agency.

Shannon, T., Giles-Corti, B., Pikora, T., Bulsara, M., Shilton, T., \& Bull, F. (2006). Active commuting in a university setting: Assessing commuting habits and potential for modal change. Transport Policy, 13 (3), 240-253.

Stanley, J. K., Hensher, D., \& Loader, C. (2009). Road transport and climate change: stepping off the greenhouse gas. Transportation Research Part A, 45(10).

Terefe, B. (2010). Greenhouse gas emissions from private vehicles in Canada, 1990 to 2007. Ottawa: Environment Accounts and Statistics Division.

Walsh, C., Jakeman, P., Moles, R., \& O’Regan, B. (2008). A comparison of carbon dioxide emissions associated with motorised transport modes and cycling in Ireland.

Transportation Research Part D(13), 392-399. 